\title{
LBGT voices in work-life research A call for research and LGBT research community
}

Jean-Charles E. Languilaire, Ph.D, Assistant Professor in Business Administration, Department of Urban Studies, Institution of Culture and Society, Malmö University (corresponding author) jean-charles.languilaire@mah.se

Neil Carey, Ph.D. Principal Lecturer, Faculty of Health, Psychology \& Social Care, Manchester Metropolitan University.

\begin{abstract}
Despite an apparent expansive inclusivity of the aims of work-life programs, there remains a fairly narrowly defined heteronormative view of the family. Alternative and non-normative perspectives of family life, and especially those pertaining to Lesbian, Bisexual, Gay and Transsexual (LGBT) identities remain relatively occluded and under-researched. The aim of this paper is to question the presence and relevance of LGBT voices and perspectives in worklife research as they seem neither visible nor on the frontline of work-life research despite their increasingly legitimate presence in organisational and societal discourses.
\end{abstract}

Key Words

LGBT, work-life management, multi-level contexts, diversity, heteronormative view, homonormative view.

\section{Résumé}

Malgré le fait que les programmes de réconciliation vie professionnelle-vie personnelle semblent s'ouvrir vers tous les employés, la vision de la famille et de la vie personnelle reste largement basée sur une norme hétérosexuelle. Les modèles alternatifs spécialement lesbiens, gays, bisexuels et transsexuels sont aussi peu présents qu'analysés. Cet article questionne la présence et la pertinence d'entendre les voies et les perspectives LBGT au sein de la recherche travaille-famille. Ceci est essentiel car ces voies et perspectives semblent peu audibles et visibles au sein de corps académique et scientifique alors que leur présence dans le discours social et organisationnel est en progression.

Key Words

LGBT, réconciliation vie professionnelle-vie personnelle, diversité, norme hétérosexuelle, norme homosexuelle. 


\section{Introduction: LBGT voices in work-life: a discrepancy between research and societal changes}

Work-life management took on a very particular shape with the increasing inclusion of women in the workforce when "double shift" syndrome as having a paid work outside home but also non-paid work at home started to be discussed (Hochschild, 1989). But the debate has long evolved since then. First, the focus was mainly on work-family conflict leading to stress, health issues and strain (See for example: Frone, Russell, \& Cooper, 1993; Greenhaus \& Beutell, 1985; Greenhaus, Collins, \& Shaw, 2003; Moorhead \& Griffin, 2001; Roos, Lahelma, \& Rahkonen, 2006). Thereafter, the focus shifted to the inclusion or integration of work and life for improved well-being (See for example: Blyton, Blunsdon, Reed, \& Dastmalchain, 2006; Demerouti, 2006; Kossek \& Lambert, 2005b; Lewis, Rapoport, \& Gambles, 2003; Sutton \& Noe, 2005). Second, policy and practice shifted from work-family interactions as an issue that was particularly problematic for women to a broader consideration of the key challenges for all employees. As a whole, work-life programs have more recently been concerned with access to work-life arrangements that enable women and men, couples with and without children, as well as singles to balance work and non-work demands for the integration of work and personal life (Poelmans \& Beham, 2008; Sutton \& Noe, 2005). Despite an apparent expansive inclusivity of the aims of work-life programs, there remains a fairly narrowly defined heteronormative view of the family. Alternative and non-normative perspectives of family life, and especially those pertaining to LGBT identities remain relatively occluded and under-researched. As an indication of this lack of research focus we can look to the occurrence of LGBT-related work presented at the two major international work-life conferences ${ }^{1}$ : the Community Work and Family (CWF) conference in 2013 in Sydney includes only 1 paper out of 166 single papers (See: Languilaire, 2013); in 2015 in Malmö it was 2 papers out of 65 papers clearly focused on it (See: Carey, 2015; Languilaire, 2015) and 1 paper indicated LGBT in the method (See: Moberg, 2015). At the Work and Family researcher network conference that gather more than 800 researchers the number are not higher. In New York in 2012, 7 papers touched LGBT, 5 of them in a specific roundtable on "same-sex partners and their families" (See: Friedlander, 2012; Horning, 2012; Languilaire, 2012; Moyer, Richardson, \& Goldberg, 2012; Widiss, 2012). Four years after in Washington, such roundtable was not existent and only 3 papers touched upon same-sex families (See: Evertsson \& Boye, 2016; Smith \& De Angelis, 2016; Weisshaar, 2016). All in all, these low figures demonstrate that there is no real catwalk for LGBT voices and less considering their diversity.

${ }^{1}$ We searched for LGBT, nested and related terms in the titles or abstracts. 
This lack of empirical research is in stark contrast with the emerging research evidence pointing to the ameliorative effects on organisational performance of having LGBT-friendly policies (Pichler, Blazovich, Cook, Huston, \& Strawser, 2015) and the concomitant growing awareness that people who identify as LGBT make up a significant proportion of the population in modern contemporary societies and therefore in work organisations. This dearth also contrasts with the growth of wider legal recognitions for LGBT family units. Indeed, largely as a result of national legislative changes, the norms about family are ostensibly and officially shifting and shifted. Such change is noticeable in how exponentially the legal right to same-sex union has come about after several years of intense political and cultural battles. The French debate and social movement on "mariage pour tous" is a visible and recent example of such evolution in Europe (See: Binet \& Rotman, 2016). The right to same-sex union started timidly with The Netherlands in 2001 and, by the end of 2009, only 6 countries had legislated for same-sex marriage. However, between 2010 and 2016, 14 additional countries including the UK, France and Spain in Europe and, significantly, the USA and South Africa had developed legal frameworks to recognise same-sex unions.

The aim of this paper is to question the presence and relevance of Lesbian, Bisexual, Gay and Transsexual (LGBT) voices and perspectives in work-life research as they seem neither visible nor on the frontline of work-life research despite their increasingly legitimate presence in organisational and societal discourses.

\section{LBGT voices in work-life research: is there an agenda for research?}

Work-life management, as one of the theoretical frames in the work-life research, focuses on how individuals are actors and makers of their life as composed of several life domains. Worklife management is widely conceptualised as a contextual process (den Dulk, 2005; Kossek \& Lambert, 2005a; Ollier-Malaterre, 2009; Poelmans \& Sahibzada, 2004) among those, the organisational and societal context but also the private or familial context of a certain individual.

In the mainstream view, work-life management starts with the belief that individuals have a "preference", even implicit, in how they ought to build their life (Ashforth, Kreiner, \& Fugate, 2000; Kossek \& Lautsch, 2012; Kossek, Lautsch, \& Eaton, 2005; Kossek, Noe, \& DeMarr, 1999) so that such preferences are to be placed along what Nippert-Eng (1996) introduced as 
the integration-segmentation continuum. On the one hand, segmentors define strict lines between their life domains because they do not accept a mixture between their life domains (Nippert-Eng, 1996; Zerubavel, 1991, 1997). On the other hand, integrators define no line and/or do not distinguish any life domains so that overlaps between work and other life domains are natural (Nippert-Eng, 1996; Zerubavel, 1991, 1997). From cognitive behaviour, the centrality of integration and segmentation became central to boundary theory in work-life (See among others: Derks, Bakker, Peters, \& van Wingerden, 2016; Methot \& LePine, 2016; OlsonBuchanan \& Boswell, 2006; Rothbard, Phillips, \& Dumas, 2005). Kossek and Lautsch (2012) view boundary management as the overall approach used by an individual to establish boundaries and attend roles in the diverse domains. They view three strategies, integration, segmentation and alternation (Kossek \& Lautsch, 2012). Bulger, Matthews, and Hoffman (2007) identify four main clusters in terms of boundary management: 1-integrators, 2-work integrators \& Personal life segmentors, 3-neutral, 4-flexible people (neither/nor). Languilaire $(2007,2009)$ views integration and segmentation as complementary so that five approaches to work-life could be identified: 1- Pushed integration; 2- moderated integration, 3- balanced preference between segmentation and integration; 4- moderated segmentation and finally 5pushed segmentation.

Based on one's preferences, individuals will engage in boundary work as mental activity and in boundary management as concrete boundary making (Kossek \& Lautsch, 2012; Kossek et al., 2005; Languilaire, 2009, 2010; Nippert-Eng, 1996). Both processes are anchored in a person-environment fit model (Edwards \& Rothbard, 1999). Indeed, the extent to which one's contexts are favourable in the creation and development of life domains is crucial for that individual in actualising a sense of his/her life as meaningful, as healthy, and as authentic as one would wish. Languilaire (2009) emphasises the role of individuals' perception and understanding of their contexts - at the individual, organisational and/or societal levels - as either a threat or opportunity in developing and managing work-life boundaries. The sense of “threat and opportunity" on one's context can be assimilated to the job demand-resource model developed in stress management (see as illustration: Xanthopouloua, Bakkera, Demerouti, \& Schaufelib, 2009) even if it can be seen as less rational and more emotional and broader than solely job related. One's understanding of his context shall enable individuals to integrate or segment different elements of their life namely their times, places, behaviours, emotions, human relations, thoughts and stress \& energy (Languilaire, 2009). For each element one can have a integrative or a segmentative approach so that as whole domains become distinctive, 
similar or overlapping (Languilaire, 2009). In other terms, life domains (such as family, work, social and private) can be then developed and managed in order for human needs to be fulfilled. Based on conservation resources theory (Grandey \& Cropanzano, 1999; Hobfoll, 1989), when, as a result of their boundary work and management, individuals obtain what they expected in terms of work-life preference, they may reproduce their strategies to obtain the same results over time. On the opposite, if they do not reach their preferences, individuals may engage in new boundary work and management. Based on the knowledge gained in work-life management and work-life boundary, we argue that the purview of work-life research be extended so as to more wholly consider LBGT perspectives. We exemplify our argument by presenting LGBT situations in three levels of context, which, we posit, highlight the imperative of attending to such perspectives in a more systematic and serious way.

\section{An agenda at the individual level?}

First, as human and social beings, individuals seek love, emotional support, belongingness and social support. In doing so, they develop and manage two major life domains: namely "family life" and "social life" (Languilaire, 2009). Firstly, the family domain is defined in and through relationships with people associated with the roles of spouse, child, parent, sibling, grandparent, cousin, uncle, aunt etc. "enabling” love, and emotional support. Secondly, the social domain is realised within and through the networks of relationships associated with those assigned to the role of friends, "enabling" belongingness and social support. We suggest that, when people from the family and social domains are accepting of non-normative sexualities, the creation and management of these two life domains may be relatively non-problematic. Indeed, it might even be safe to argue that there is little difference for those identifying as LGBT in comparison with their heterosexual counterparts.

However, challenges are likely to be much more significant and marked when LGBT-identified people are confronted by, and find themselves discordantly aligned with, a dominant and strong heterosexual norm. The existence of strong heterosexual norming may lead to family rejection and to broken friendships when a LBGT person decides to "come out" as a means of integrating their life domains, thus fulfilling the desire to be authentic, to be oneself in both the family and social domains. People who face rejection from their "original" family and social life must, in time, develop new family and social domains in order to palliate the effects of breaking with biological or established bonds. For example, newly formed relationships with LGBT community members may be transformed into those that more closely resemble family- 
associated relations. Narratives of young adults arriving on the (mainly urban) LGBT scene following either a geographical and/or emotional rift with former milieu abound. Such in-bound 'scene migrants' may look for guidance and emotional support from contemporaries within the LGBT community as a substitute for that previously provided by familial relationships. (see for example Q\&A section of gay magazine such as Têtu in France, QX in Sweden, Out Magaxine and Attitude Magazine in the UK). In such circumstances, LGBT community members may become essential to facilitate "integration", making such people feel that they belong and, at the same time, "teach" others a sense of LGBT culture. These 'teachers' may be perceived as more than 'mere' friends or buddies.

From a boundary perspective, and in the kinds of circumstances outlined here, community becomes at one and the same time, one's family and social life. Thus, the centrality of the community domain cannot be overstated. This aspect may complement the categories of worklife identity as work-centric, family-centric, dual-centric and other non-work centric presented by Kossek and Lautsch (2012). On the one hand "LBGT" may have a "community-centric identity" and their "family-centric identity may be blurred with the "community-centric identity". On the other hand, one could also imagine that existing friendships may take a new role in one's life if those friends are now accepting of one's non-normative sexuality. Whereas prior to coming out such friendships might have been of second rank given that they were mediated through "the closet" (Brown, 2000). In Kossek and Lautsch (2012) words, this will mean the development of social-centric identity as in that case the social life is thus also redesigned through coming out. Beyond providing such examples and speculating about the possible consequences of rejections and the re-forging of relationships that blur and blend their family and social domains, we encourage more debate and research in order to understand if, how and why individuals who do not perceive their individual context as favourable, reconstruct family and social life domains by developing new relationships enabling the needs of love, belongingness and support to be fulfilled. The domain identification frame (Kossek \& Lautsch, 2012) may be worth to be explored to theorise on that aspect. Additionally, we also posit that the (re)creation and (re)development of new family and social domains can become a challenge for LBGT people that, in turn, may require new or special resources. We thus encourage research from a resource-based perspective using resources-demand model (see: Xanthopouloua et al., 2009) or conservation or resources theory (See: Hobfoll, 1989) applied to work-life management so as to ensure the direct relevance of work-life education for LBGT people. However, and in addition, we strongly urge that the lens for any such research/education 
be (re)framed so that the 'problem' (and any attendant 'solutions') lies in the macro and systemic socio-cultural realm rather than at the individual level, making LGBT work-life balance an issue of societal responsibility.

\section{An agenda at the organisational level?}

Second, if we turn now to the organisational level. An individual's work domain may be defined in and through that network of relationships developed between them and their managers and colleagues in the context of a psychological and quality contract (Languilaire, 2009). In organisations, legislation protects individuals from discrimination. However, beyond explicit statement and practice of legal frameworks, the culture or climate as "LGBT friendly" is central for LGBT-identifying people's work-life management (See: Pichler et al., 2015). Let's illustrate with two cases.

- An LGBT-identifying person who wishes to integrate her/his life domains; attempting to be as authentic as possible by aligning her/his sense of self both in and outside of work. However, this individual perceives the organisational climate as hostile towards non-normative sexualities. In this case, (s)he will have to develop tactics so as not to uncover his/her non-normative sexual identity. For example, while colleagues may openly talk about girl/boyfriends, husbands, wives and kids, the LGBT-identifying person may well have to exercise a great deal of care in not talking about their significant other and/or adopt identifiably gender-neutral terms such as 'partner'. Alternatively, and perhaps more negatively, such LGBT employee may have to deny his/her significant other or find fake partners when attending organisational occasions that implicitly demand a family showing.

- The same integrative organisational pressures which somehow are, contemporaneously, put forward as archetypes of work-life may also be perceived for separators as threats and may require specific tactics. Indeed, LGBT-identifying employees who adopt a segmenting approach to work-life management may feel the need to develop similar parades when organisations compel employees to blend work and other life domains. The art of saying "no" to after-work, to taking work at home and other is often presented as challenge. (Languilaire, 2009) It is worth noticing that such situation is not solely relevant for who are LGBT-identifying. Those heterosexual employees who also wish to segment may experience similar strains. And yet, the threats and consequent strains for LGBT-identifying employees who find themselves placed in a hostile work environment may be more challenging than for their 'straight' heterosexual peers. 
From a theoretical perspective, the misfit between the employee's work-life preferences and strategy and their perception of the work environment is central. This was coined a as the person-environment fit and the centrality of alignment of organisational policies (Edwards \& Rothbard, 1999; Kossek, 2003; Rothbard et al., 2005). In the case of LGBT, both the misfit between the employee's integrative work-life strategy and their perception of the work environment as discriminatory or hostile, and the misfit between the individual segmentative work-life strategy in the context of an integrative organisational culture, may be associated with surface acting leading, in the long term, to emotional and cognitive dissonances (Fineman, 1993; Hochschild, 1989; Kossek \& Lautsch, 2012). Such effects can lead to individual health consequences as well as to performance consequences for the organisation and, thus, for society more widely.

All things considered, when it comes to the organizational context, we would like work-life research to stimulate a better understanding of how unwritten organisational norms affect worklife management for LGBT-identifying employees. For example, research might attend to: the facets of organisational culture that require LGBT-identifying employees to adopt defensive strategies in managing work-life balance; exploring what is at stake for employees in having to develop and sustain such tactics; or, examining the impacts on organisational performance when employees feel the need to adopt such coping mechanisms. The recent article and quiet frankly one the only paper in this last subject is entitled "Do LGBT-supportive Corporate Policies Enhance Firm Performance?" By Pichler et al. (2015). We do encourage more. Alternatively, adopting a more positive and labour-aligned approach, research might explore: what is at stake in and for organisations in retaining such LGBT hostile cultures and what strategies might be adopted in combating such hostility; whether and how LGBT employees generate a sense of personal power/control in adopting defensive tactics in such hostile organisational environments.

\section{An agenda at the societal level?}

Third, we want to highlight how societal contexts have a bearing on how LGBT-identifying people manage work-life dynamics. Recent 'progressive' socio-cultural changes in respect of same-sex marriage and union might be viewed as a cultural strategy to normalise and equivalise work-life management across LGBT-identifying people and their heterosexual counterparts. As O’Brien (2008, p. 498) argues: 
“queer cultures appear more and more similar in values and lifestyle choices to those whose lives reflect the values and resources of a western heterosexual middleclass. This trend is reflected sloganistically in the shift away from the historically recent call to action, 'we're here, we're queer, get used to it', toward the more banal and assimilationist, 'we're here, we're queer, let's go to Ikea'."

However, the seeming shift towards equality between heterosexual and LGBT-identifying people evident at a macro level in many Western/Northern national contexts, belies many of the complexities inherent in how such socio-cultural dynamics play out and are experienced at the micro and mundane levels - including in respect to the management of work and life realms. The fight for (near) equal sexual citizenship rights in western heteronormative societies is totemistically cast as a righteous fight against a pervasive and monolithically experienced homophobia. Notwithstanding the level and intensity of homophobia experienced by LGBTidentifting people, there is ample evidence to show that homophobia operates and is subjectively experienced in radically different ways (O'Brien, 2008) depending on the gender, class, race and disability status of those on the receiving end of it (See: Ferguson, 2012; Nagel, 2003; Taylor, 2011). Indeed, the modern gay rights movement is much criticized for how it almost exclusively tends to speak to and for a narrow constituency of white, middle-class, ablebodied males in urban contexts. Such criticisms of a modern gay rights movement cohere in Duggan (1994) formulation of 'homonormativity', a term that signifies the privilege accorded this particular constituency of non-normative sexual citizens in western neo-liberal sociopolitical contexts which render them as ideal citizen-consumer-subjects who adopt an apolitical lifestyle characterized by domestic consumption and privatized sexual practice. This paragon of the respectable and acceptable 'good gay' is held as testimony to extending the franchise of citizenship to homosexuals. More importantly, this homonormative figure is positioned as the mark against which all those who identify under the umbrella term of LGBT are measured and often found wanting (See: Bell \& Binnie, 2000, 2006).

This homonorm has consequences for how the whole range of diverse LGBT identities are experienced - not least in the management of work-life. For example, the options for either integrating or segmenting work-life realms are likely to be expansive for those gay males who work in higher-status and professionally-qualified occupations where work-life boundaries are negotiated in more formal ways and within highly liberal work contexts where a level of respectful distance is expected and can be assumed - at least on the surface level of interaction. 
The availability of choice afforded this white middle-class gay man will differ significantly from a variety of other gay men including those who hail from lower socio-economic groups, from communities that are expound less LGBT tolerant attitudes, or those work in semi-skilled and manual occupations, or those occupations considered traditionally masculine. Such intersectional differences also parallel those likely to impact the practice and experience of work-life management strategies adopted by those identifying as lesbian, bisexual and trans.

From a pure work-life boundary perspective in work-life research, this may imply that a LGBT person may strengthen his/her domain's boundaries because segmentation is being perceived as societally wished whereas this person would love to integrate and be true to him/herself also in the societal sphere. This connects to the "closeted" gay view. Without going into and cautioning the stigmatization about how closeted homosexual or LBGT lives may be characterised as being dramatically split and compartmentalized between public performances and some carefully chosen private contexts lived in "the closet", this may be certainly the reality for still many LGBT person. The closet "tropes on meanings of concealment, elsewhereness-yet-proximity, darkness and isolation, with the potential for movement or escape" argues Brown (2000, p. 8). Sedgwick (1994, p. 48) asserts that "the closet is the defining structure for gay oppression in this [twentieth] century". Some new forms of oppression may be affecting work-life management today. This is nowadays illustrated with how media and people in social media react to coming out announcement of celebrities. On the one side a certain minority feels that this is central for societal advancement but still a majority often diminishes its importance and relays it as "private issue". As a whole, tactics to work-life management in the societal sphere may, here again, be associated with "surface acting" leading to emotional dissonance and its associated consequences on health for LGBT.

All together we call here for further research exploring the impact of socio-legal changes on the actual work-life management of LGBT-identified people. Research can get inspiration in paper such as Block, Malin, Kossek, and Holt (2006). Few papers have been starting to address that aspect especially during the roundtable at Work and Family Researchers Network Conference, in 2012 (Friedlander, 2012; Widiss, 2012). However, we are clearly arguing that such research work be critically mindful of the differential impacts that changes in the sociolegal contexts have on the heterogeneous group often subsumed under the LGBT category. Here we underscore the now well-worn warning promoted by a range of researchers who attend to 
the importance that intersectionality of a diverse range of identity dimensions play in researching social phenomena.

\section{Final reflections on researching LGBT voices but not norming LGBT work-life management}

To sum up, we illustrated that sexual identity may be a factor explaining differences between LGBT and heterosexual people in work-life management at different contexts. We underlined three contexts, individual, organisational and societal and we do believe that they are interacting in one's life as each individual moves between them on daily basis. Challenges may thus be greater when not all the contexts are "accepting" and when contradictions exist between them. We thus urge work-life researchers to include in their research a clearer and more visible place to sexual identity as it can affect individual, organization and society health and performance. With inspiration of Pitt-Catspouphes and Googins (2005), we claim that having a LGBT perspective on work-life management is essential to Corporate Social Responsibility but even overall to sustainability. In other terms such research is a way to answer EU's ambition on conditions of quality of life for all its citizens:

"Our subjective perception of well-being, happiness and life satisfaction is fundamentally influenced by our ability to engage in and spend time on the activities we like. The importance attributed by modern societies to recreational and cultural activities and worklife balance underlines the role leisure and social interactions play in quality of life" (Eurostat, 2015, p. 135)

More specifically we envision research on LGBT population both from a deductive, inductive or iterative approach. We envision research on LGBT population with and without comparing with heterosexual population. We envision multi-level research on LGBT population to capture how the LBGT identity affects the whole work-life interface and how the different contexts are playing a role in work-life management. We envision case studies, multiple case studies and also cross sectional and even cross-country research. We hope that a rich and diverse set of research could enable the development of LGBT models for work-life management as a way to make the LGBT voices heard. The centrality of this research agenda is however not to be seen as a way to develop a new norm in work-life management. Indeed as alluded above, and in thinking through our call for a research agenda that more seriously and visibly gives attention to the needs and experiences of LGBT-identifying people in relation to work-life management, we would like to make a further plea in relation to this agenda. 
As we noticed while reflecting on the LGBT perspectives, challenges in terms of work-life management for LGBT person occurs to be of different nature compare to heterosexual people when a gap occurs between the "norms" of the level and the "individual" need to be authentic at that level (See: Edwards \& Rothbard, 1999). This relates to "coming out" as breaking norms. Most pertinent to this paper are the ways in which the coming out story tends to homogenise non-normative sexual difference.

Crawley and Broad (2004) analyse the ways in which the coming out:

"focuses the public discussion about sexuality into "types" of people (characters = victims and villains) with a limited number of "truths" (narrative plots) that can be spoken about them. As such, the formulaic nature of the narrative decreases the variability and diversity of experiences that LGBT people might otherwise narrate...(This reliance on the formula story tends to) create a coherent narrative [that] ultimately works against the possibility of envisioning LGBT people as fully unique, diverse, and nontypical" (Crawley \& Broad, 2004, pp. 49-50)

In other terms, what might be at stake in instantiating something called LGBT work-life management is that we may reinforce the hetero- and homo norms. Additionally, the homonorm outlined above - and its unsettling across the insectional nexes of gender, social class, race, disability and so on - raises also a critical concern in relation to any suggestion that there is a heteronorm about work-life, but is there? The disturb notion of LGBT - diversity as much as homogeneity speaks in parallel to the complexities that are overlooked by failing to attend to the diversity that coheres (silently) in the heteronorm.

To conclude, the shift in socio-legal norms about family and the extent to which mainstream work-life research fails to represent the existence of a specific work-life management model for LGBT people, is not to deny. Nor is to deny that even some of work-life researchers are interested in the issue and are working on LGBT related issue, more can be done. In this paper we, Jean-Charles and Neil as researcher who appears to be intrinsically and personally interested by LGBT issue, hoped to stimulate a so-called LGBT research multi-level agenda in work-life research to enable LGBT voices to be heard. For such agenda to be reality, we want to dare individual researchers who have stake in LGBT questions and have interest in work-life management to raise their voices. Together we can develop a strong LGBT work-life community of research. Nonetheless, it is not to deny that the diversity voices in the heteronorm 
must also be heard. We thus alert on the dangers that could emerge when LGBT knowledge is translated into norms about work-life management. To avoid that trap, we wish organisations to be active in a LBGT community of practice on work-life management so that a dialogue can be developed. To close this article and ironically to further open this debate, we, Jean-Charles and Neil as employee, do believe neither in a "LGBT-friendly" workplace nor in a "heterofriendly" workplace. We above all believe and envision in "humanistic workplace" where everyone's work-life management is valued and respected as long time suggested by Kirchmeyer (1995).

Ashforth, B. E., Kreiner, G. E., \& Fugate, M. (2000). All in a day's work: boundaries and micro role transitions. Academy of Management Review, 25(3), 472-491.

Bell, D., \& Binnie, J. (2000). The Sexual Citizen: Queer Politics and Beyond. Cambridge, UK: Polity Press.

Bell, D., \& Binnie, J. (2006). Geographies of sexual citizenship. Political Geography, 25(8), 869-873.

Binet, E., \& Rotman, C. (2016). La bataille du mariage pour tous. Paris: Books Edition.

Block, R. N., Malin, M. H., Kossek, E. E., \& Holt, A. (2006). The legal and administrative context of work and family leave and related policies in the USA, Canada and the European Union. In F. Jones, R. J. Burke, \& M. Westman (Eds.), Work-Life Balance: A Psychological Perspective (pp. 39-68). Hove, East Sussex: Psychology Press.

Blyton, P., Blunsdon, B., Reed, K., \& Dastmalchain, A. (Eds.). (2006). Work-life integration: international perspectives on balancing multiple roles - International Perpectives on the balancing of multiple roles. Houndsmills: Palgrave Macmillan.

Brown, M. P. (2000). Closet Space: Geographies of Metaphor from the Body to the Globe (1 ed.). London, New York: Routledge.

Bulger, C. A., Matthews, R. A., \& Hoffman, M. E. (2007). Work and Personal Life Boundary Management: Boundary Strenght, Work/personal life Balance and the segmentation-integration continuum. Journal of Occupational and Health Psychology, 12(4), 365-375. doi:10.1037/1076-8998.12.4.365

Carey, N. (2015). Diversity Within LGBT Communities. Paper presented at the 6th International Community Work and Family Conference, Malmö, Sweden.

Crawley, S. L., \& Broad, K. L. (2004). Be Your(Real Lesbian)Self: Mobilizing Sexual Formula Stories through Personal (and Political) Storytelling. Journal of Contemporary Ethnography, 33(1), 39-71. doi:10.1177/0891241603259810

Demerouti, E. (2006). Human resource policies for work-personal life integration. In R. J. Burke \& C. L. Cooper (Eds.), The Human Resources Revolution, Why putting people first matters (pp. 147-169). Oxford: Elsevier.

den Dulk, L. (2005). Workplace work-family arrangements: a study and explanatory framwork of differences between organisations provisions in different states. In S. A. Y. Poelmans (Ed.), Work and Family: An International Reseach Perspective (pp. 211-238). Mahwah, New Jersey: Lawrence Erlbaum Associates, Publishers.

Derks, D., Bakker, A. B., Peters, P., \& van Wingerden, P. (2016). Work-related smartphone use, work-family conflict and family role performance: The role of segmentation preference. Human Relations, 69(5), 1045-1068.

doi:10.1177/0018726715601890

Duggan, L. (1994). Queering the State. Social Text, 3, 1-14. 
Edwards, J. R., \& Rothbard, N. P. (1999). Work and family stress and well-being: an examination of person-environment fit in the work and family domains. Organizational Behavior and Human Decision Processes, 77(2), 85-129. doi:10.1006/obhd.1998.2813

Eurostat. (2015). Quality of Life - Facts and Views. (ISBN 978-92-79-43616-1). European Union.

Evertsson, M., \& Boye, K. (2016). The Transition to Parenthood as a Critical Juncture for Gender Inequality in the Home and in the Labor Market - Comparing Heterosexual Couples to Female Same-Sex Couples. Paper presented at the Work and Family Researchers Network, Washington DC, USA.

Ferguson, S. J. (Ed.) (2012). Race, Gender, Sexuality, and Social Class: Dimensions of Inequality. London; Thousand Oaks: Sage Publications.

Fineman, S. (1993). Organizations as emotional arenas. In S. Fineman (Ed.), Emotion in Organizations. London. Thousand Oaks. New Delhi: Sage Publications.

Friedlander, D. (2012). Internalized Homophobia and Gay Parenting - Gay Parenthhooild in a Changing Society: The Israeli Current State of Affairs. Paper presented at the Work and Family Researchers Network, New York, USA.

Frone, M. R., Russell, M., \& Cooper, M. L. (1993). Relationship of work-family conflict, gender, and alcohol expectancies to alcohol use/abuse. Journal of Organizational Behavior, 14(6), 545-558. doi:10.1002/job.4030140604

Grandey, A. A., \& Cropanzano, R. (1999). The Conservation of Resources Model Applied to Work-Family Conflict and Strain. Journal of Vocational Behavior, 54(2), 350370. doi:10.1006/jvbe.1998.1666

Greenhaus, J. H., \& Beutell, N. J. (1985). Sources of conflict between work and family roles. The Academy of Management Review, 10(76-88). doi:10.5465/AMR.1985.4277352

Greenhaus, J. H., Collins, K. M., \& Shaw, J. D. (2003). The relation between work-family balance and quality of life. Journal of Vocational Behavior, 63, 510-531. doi:10.1016/S0001-8791(02)00042-8

Hobfoll, S. E. (1989). Conservation of ressources: a new attempts at conceptualizing stress. American Psychologist, 44(3), 513-524.

Hochschild, A. R. (1989). The second shift: working parents and the revolution at home. New York, N.Y.: Viking.

Horning, K. (2012). Mothers Negotiating Work-Family Conflict: Similarities and Differences for Women in Same and Opposite Sex Partnerships Paper presented at the Work and Family Researchers Network, New York, USA.

Kirchmeyer, C. (1995). Managing the work-nonwork boundary: an assessment of organizational responses. Human Relations, 48(5), 515-536. doi:10.1177/001872679504800504

Kossek, E. E. (2003, June 16-18). Workplace policies and practices to support work and families: gaps in implementation and linkages to individuals and organizational effectiveness. Paper presented at the Workforce/workplace mismatch: work, family, health, and well-being, Washington D.C.

Kossek, E. E., \& Lambert, S. J. (2005a). "Work-family Scholarship": voice and context. In E. E. Kossek \& S. J. Lambert (Eds.), Work and life integration: Organizational, cultural and individual perspectives (pp. 3-17). Mahwah, New Jersey: Lawrence Erlbaum Press. 
Kossek, E. E., \& Lambert, S. J. (Eds.). (2005b). Work and life integration : organizational, cultural and individual perspectives. Mahwah, New Jersey: Lawrence Erlaubaum Associates, Publishers.

Kossek, E. E., \& Lautsch, B. A. (2012). Work-family boundary management styles in organizations - A cross-level model. Organizational Psychology Review, 2(152171). doi:10.1177/2041386611436264

Kossek, E. E., Lautsch, B. A., \& Eaton, S. C. (2005). Flexibility enactment theory: implications of flexibility type, control, and boundary management for work and family effectiveness. In E. E. Kossek \& S. J. Lambert (Eds.), Work and life integration: Organizational, cultural and individual perspectives (pp. 243-261). Mahwah, New Jersey: Lawrence Erlbaum Press.

Kossek, E. E., Noe, R. A., \& DeMarr, B. J. (1999). Work-family role synthesis: individual and organizational determinants. The International Journal of Conflict Management, 10(2), 102-129. doi:10.1108/eb022820

Languilaire, J.-C. E. (2007). Segmentation and Integration of Work and Personal Life: How do French Middle-Managers make choices? Paper presented at the 2nd International Conference on Work and Family (ICWF), Harmonizing work, family and Personal Life: Strategies for crossing boundaries, Barcelona, Spain.

Languilaire, J.-C. E. (2009). Experiencing work/non-work - Theorising individuals' process of integrating and segmenting work, family, social and private. (Doctoral), Jönköping University, Jönköping International Business School.

Languilaire, J.-C. E. (2010). Middle-Managers Work/non-work Boundaries; exploring individuals' experiences to act socially responsible and develop healthy organisations. In P. Dobers \& A. Söderholm (Eds.), Corporate Social Responsibility: Challenges and Practices (pp. 355). Stockholm: Santérus Academic Press Sweden.

Languilaire, J.-C. E. (2012). The Work/Non-Work Experience: What About Gay Homosexuals? An Explorative Study of Gay Men in Sweden. Paper presented at the Work and Family Researchers Network, New York, USA.

Languilaire, J.-C. E. (2013). The work/non-work experience: what about a gay experience? Setting a temptative research agenda. Paper presented at the 5th International Community Work and Familty Conference, Sydney, Australia.

Languilaire, J.-C. E. (2015). Work/Non-Work Process and Outcome for Alternative Lifestyles. Paper presented at the 6th International Community Work and Family Conference, Malmö, Sweden.

Lewis, S., Rapoport, R., \& Gambles, R. (2003). Reflections on the integration of paid work and the rest of life. Journal of Managerial Psychology, 18(8), 824-842.

Methot, J. R., \& LePine, J. A. (2016). Too Close for Comfort? Investigating the Nature and Functioning of Work and Non-work Role Segmentation Preferences. Journal of Business and Psychology, 31(1), 103-123. doi:10.1007/s10869-015-9402-0

Moberg, Y. (2015). How does the Gender Composition in Couples affect the Division of Labor After Childbirth? Paper presented at the 6th International Community Work and Family Conference, Malmö, Sweden.

Moorhead, G., \& Griffin, R. W. (2001). Managing stress and the work-life balance. In G. Moorhead \& R. W. Griffin (Eds.), Organizational behaviour - managing people and organizations (Vol. 9, pp. 220-240). Boston, New York: Houghton Miffin Company.

Moyer, A., Richardson, H., \& Goldberg, A. (2012). You Try to be Superman and You Don't Have to Be: Gay Adoptive Dads' Challenges With Work/Family Balance. Paper presented at the Work and Family Researchers Network, New York, USA. 
Nagel, J. (2003). Race, Ethnicity, and Sexuality: Intimate Intersections. OUP USA: Forbidden Frontiers.

Nippert-Eng, C. E. (1996). Home and work : negotiating boundaries trough everyday life. Chicago \& London: The University Chicago Press.

O’Brien, J. (2008). Afterword: Complicating Homophobia. Sexualities, 11(4), 496-512. doi:10.1177/1363460708093457

Ollier-Malaterre, A. (2009). Organizational work-life initiatives: context matters. Community, Work \& Family, 12(2), 159-178. doi:10.1080/13668800902778942

Olson-Buchanan, J. B., \& Boswell, W. R. (2006). Blurring boundaries: Correlates of integration and segmentation between work and nonwork. Journal of Vocational Behavior, 68, 432-445. doi:10.1016/j.jvb.2005.10.006

Pichler, S., Blazovich, J., Cook, K., Huston, J., \& Strawser, W. (2015). Do LGBT-supportive Corporate Policies Enhance Firm Performance? Academy of Management Proceedings. doi:10.5465/AMBPP.2015.15078

Pitt-Catspouphes, M., \& Googins, B. (2005). Recasting the work-family agenda as corporate social responsibility. In E. E. Kossek \& S. J. Lambert (Eds.), Work and life integration: Organizational, cultural and individual perspectives (pp. 469-490). Mahwah, New Jersey: Lawrence Erlbaum Press.

Poelmans, S., \& Beham, B. (2008). The moment of truth: Conceptualizing managerial work-life policy allowance decisions. Journal of Occupational \& Organizational Psychology, 81(3), 393-410. doi:10.1348/096317908X314865

Poelmans, S., \& Sahibzada, K. (2004). A multi-level model for studying the context and impact of work-family policies and culture in organizations. Human Resource Management Review, 14, 409-431. doi:10.1016/j.hrmr.2004.10.003

Roos, E., Lahelma, E., \& Rahkonen, O. (2006). Work-family conflicts and drinking behaviours among employed women and men. Drug and Alcohol Dependence, 83, 49-56. doi:10.1016/j.drugalcdep.2005.10.009

Rothbard, N. P., Phillips, K. W., \& Dumas, T. L. (2005). Managing multiple roles: workfamily policies and individuals' desires for segmentation. Organization Sciences, 16(3), 243-258. doi:10.1287/orsc.1050.0124

Sedgwick, E. K. (1994). Epistemology of the Closet. London: Penguin Books Ltd.

Smith, D., \& De Angelis, K. (2016). Don't Ask, Don't Want To Know: A Research Agenda for Same-Sex Military Families. Paper presented at the Work and Family Researchers Network, Washington DC, USA.

Sutton, K. L., \& Noe, R. A. (2005). Family-friendly programs and work-life integration: more myth than magic? In E. E. Kossek \& S. J. Lambert (Eds.), Work and Integration : Organanizational, Cultural and Individual Perspectives (pp. 151-169). Mahwah, New Jersey: Lawrence Erlaubaum Associates, Publishers.

Taylor, Y. (2011). Sexualities and class. Sexualities, 14(1). doi:10.1177/1363460710390559

Weisshaar, K. (2016). Earnings Equality and Relationship Stability for Same-Sex and Heterosexual Couples. Paper presented at the Work and Family Researchers Network, Washington DC, USA.

Widiss, D. (2012). Disaggregating Sex, Gender, and the Law of Marriage: Using the Variable Legal Rights of Same-Sex Couples as a Natural Experiment. Paper presented at the Work and Family Researchers Network, New York, USA.

Xanthopouloua, D., Bakkera, A. B., Demerouti, E., \& Schaufelib, W. B. (2009). Reciprocal relationships between job resources, personal resources, and work engagement. Journal of Vocational Behavior, 73(3), 235-244. doi:10.1016/j.jvb.2008.11.003 
Zerubavel, E. (1991). The fine line: making the distinction in everyday life. Chicago: The university of Chicago Press.

Zerubavel, E. (1997). Social mindscapes: an invitation to cognitive sociology. Cambridge, Massachusetts: London, England: Harvard Univerity Press. 